Review

\title{
The effects of exercise training on physical, physiological and psychological risk factors of patients with cardiovascular disease
}

\author{
Mahboubeh Ghayour Najafabadi ${ }^{1}$, Amir Sobhrakhshan Khah ${ }^{2}$, Jennifer Parent-Nichols ${ }^{3}$ \\ ${ }^{1}$ University of Tehran, Tehran, Iran \\ ${ }^{2}$ Tehran University of Medical Sciences, Tehran \\ ${ }^{3}$ Tufts University School of Medicine, Boston, USA
}

Received 21 February 2021, Revised 23 May 2021, Accepted 26 July 2021

(C) 2021, Russian Open Medical Journal

Abstract: Background - Exercise training is an important component of wellness for individuals diagnosed with cardiovascular disease (CVD). Exercise may have an effect on cardiovascular risk factors such as hypertension, lipid levels, and other associated physical, psychological, and physiological risk factors. Exercise intensity may further impact those risk factors.

Aim - This narrative review of the literature aims to identify the effect of regular physical exercise on modifying risk factors for CVD and increased morbidity and mortality related to CVD.

Methods - Published English-language papers from 2011 to 2020, available in Scopus, PubMed, Cochrane, Google Scholar, and Thompson were included in this review. Keywords for this search were exercise training, cardiovascular disease, hypertension, physical function, physiological, and psychological risk factors.

Conclusions - Exercise training may be a cost-effective intervention that improves the physical, physiological, and psychological risk factors and the motor function of patients with cardiovascular disease.

Keywords: exercise training, motor function, cognitive function, cardiovascular disease.

Cite as Ghayour Najafabadi M, Sobhrakhshan Khah A, Parent-Nichols J. The effects of exercise training on physical, physiological and psychological risk factors of patients with cardiovascular disease. Russian Open Medical Journal 2021; 10: e0310.

Correspondence to Amir Sobhrakhshan Khah. Address: Sepehr Heart Center, Baharloo Hospital, Tehran University of Medical Sciences, Tehran, Iran.

\section{Introduction}

Cardiovascular disease (CVD) has a direct impact on public health. It is the leading cause of death in Iran and the burden of this disease is great [1]. The physical and psychological factors associated with CVD may have a significant negative effect on mobility and quality of life [2,3]. Risk factors related to CVD include the physical hypertension, diabetes mellitus, lipid profiles, and endothelial dysfunction, and the psychological depression. Understanding the physical and psychological risk factors related to regular exercise training would assist the prescription of safe and effective rehabilitation programs for individuals with CVD.

Atherosclerosis, a primary contributor to CVD, can lead to serious medical complications including cerebral vascular accident and myocardial infarction [4]. Previously, atherosclerosis was recognized as a lipid disorder. Recently, atherosclerosis has been proposed to be an immune response and involve the activation of many types of cells [5]. Consistent physical activity has been shown to havea positive cardiovascular effect, including on atherosclerosis [6]. Regular exercise training has been shown to improve quality of life and decrease mortality in individuals with CVD by $27 \%$ [7]. Lack of adequate physical activity is the leading cause of cardiovascular disease (CVD) mortality, especially in developing countries [8-10].
Activityuidelines for patients with CVD include exercise ata moderate intensity for $30 \mathrm{~min} /$ day 4-5 times weekly [11]. For individuals with CVD, low to moderate intensity exercise has been shown to be an important component in their rehabilitation. A meta-analysis on the impact of exercise for individuals with CVD revealed that a very short period of exercise training (2.5 hours/week) had a greater positive impact on CVD risk factors than no exercise training. Further, two and a half hours of physical activity eachweekwas effective in reducing mortality risk by $19 \%$. Participation in 7 hours per week of moderate activity was shown to reduce the mortality risk by $24 \%$ [12].

While physiological factors associated with CVD may be mitigated with exercise, psychological factors should be considered as well. In a public survey of 419 adults with CVD, a high prevalence of depression was seen [13]. In 2009, a longitudinal study, showed that controlling blood pressure with regular exercise could mitigate some cognitive dysfunction related to CVD [14].

While previous research has shown the impact of exercise on specific physical and psychological risk factors of CVD, this narrative review aims to place a more comprehensive lens on the impact of regular physical exercise on modifying physical, physiological, and psychological risk factors for CVD and increased morbidity and mortality related to CVD. 


\section{Methods}

A narrative review of the research literature among published, English language papers from 2011 to 2020 was conducted using the terms, cardiovascular disease, exercise training, CVD, physical function, physiological function. Terms were searched in isolation and in all combinations. Data bases searched included Scopus, PubMed, Embase, Google Scholar, and Web of Sciences. Following this search, papers where the methodology or quality of data collection were unclear were excluded.

\section{Results}

\section{Effect of Exercise Training on Cardiovascular Risk Factors}

Hypertension. Hypertension is an important risk factors for CVD, cerebrovascular accident (CVA), heart failure, and other vascular diseases. Worldwide, nearly $54 \%$ of CVAs are related to hypertension [15].

Regular aerobic exercise has been shown to be important interventions in the prevention and treatment hypertension. A systematic review of randomized clinical trials indicated that aerobic exercise training leads to reductions in resting BP of 5-7 $\mathrm{mmHg}$ and the reductions appear to be more pronounced in hypertensive subjects [15].

A 2020 randomized controlled trial (RCT), showed 4 months of regular exercise training for patients with heart related issues had a positive effect on the peripheral autonomic function and hypertension [16]. Another 2020 reviewconfirmed the positive effects of exercise training on hypertension and highlighted the importance of attention to patient safety during exercise performance [17].

Diabetes Mellitus. Diabetes mellitus, type 2 diabetes, is also a risk factor for CVD. Regular exercise training can improve glucose tolerance in patients with type 2 diabetes. Physical activity can increase the insulin sensitivity of tissue and decrease the glycated hemoglobin ( $\mathrm{HbA1C}$ ) [18]. Patients diagnosed with type 2 diabetes who followed a regular exercise training regime both decreased body mass and decreased the incidence of diabetes type 2 by more than 50\% [19]. Additionally, regular exercise has been shown to decrease insulin resistance, lipid levels, blood pressure and weight, and improve glucose control. Exercise may also have antiinflammatory effects, increasing IL6 and decreasing proinflammatory agents and TNF [20].

A 2017 review of 15 papers concluded exercise training had a positive effect on CVD. However, the intensity and pattern of that exercise training remain unclear for patients with CVD [20]. In a 2020 randomized controlled trial exercise was found to be a costeffective intervention that had positive effects on both type 2 diabetes and ischemic heart diseases [21].

Low and high-density lipids. The levels of low and high density lipids are known as important risk factors related to CVD [22]. A 1999 meta-analysis of 31 randomized control trials showed that regular exercise positively impacted lipid levels, including low and high density lipids, triglycerides, and cholesterol. While the studies included in this meta-analysis had differing study designs, finding across studies were similar [23]

A 2016 randomized controlled trialrevealed regular exercise training at moderate intensity was effective on the body composition and lipid profile of patients with coronary heart disease, a type of CVD [24]. A 2020 randomized control trial of 50 patients with CVD showed eight weeks of controlled aerobic exercise training had a positive effective on the lipid profile of patients with CVD [25].

Endothelial Dysfunction. Endothelial dysfunction, another related risk factor for CVD, has been identified in individuals who do not engage in exercise training [26]. Exercise training has been have a direct impact on the endothelial system, improving the function of the heart and vessels [27]. A 2017 studyshowed that target-based exercise training positively affected endothelial dysfunction in patients with CVD [28]. A 2017 study found engaging in 4 weeks of regular engagement in aerobic and stretching exercise could improve could improve vascular endothelial dysfunction in patients with CVD [29].

Depression. Depression, while not a risk factor for CVD, is a common related experience for patients with CVD. Depression is responsible for a great global burden [30] and is also independently associated with increased cardiovascular morbidity and mortality. Increased incidence of depression among individuals with CVD may be related to the perception of impaired physical abilities and the impact the diagnosis may have on social interactions and connectedness. [31,32].

A 2019 review paper found depression is a prevalent and increasing issue that affects $10 \%$ of the general population, likely higher among patients with heart issues, including CVD [32]. The positive effect of regular exercise training on the prevention or treatment of depression has been reported. A 2018 meta-analysis of 27 randomized control trials concluded regular physical activity, including different types of exercise training, improved feelings of well-being of patients with CVD [33].

\section{Application of Exercise Trainings in Cardiovascular Disease}

Exercise training is an important element in the rehabilitation of patients with CVD. It has been shown to improve physiological, psychological, and physical contributors [34]. Further, a negative correlation between aerobic training and mortality has been established [35]. Two recent meta-analyses showed the positive effects of both aerobic and resistance training on heart performance $[36,37]$ andboth aerobic and resistance training have been shown to be safe interventions. $[38,39]$. Specificallyin cardiac rehabilitation (CR), exercise at a moderate intensity under supervision of a physician has been shown to be safe [40]. Low- to moderate-quality evidence supports that $C R$ reduces the risk of all-cause hospital admissions and may reduce heart failure specific hospital admissions in the short term (up to 12 months). CR may confer a clinically important improvement in health-related quality of life [40].

Regular aerobic exercise training with moderate intensity has a significant impact on myocardial infarction and it should be considered as one of the most important methods to address mortality in patients with CVD $[41,42]$. Even a simple pattern of home-based exercise training may be effective in treating coronary artery disease [43]. A 2017 meta-analysis suggestedexercise training should focus on optimizing total energy expenditure rather than on one specific training characteristic. This aim should be considered for cardiac rehabilitation as well [44].

\section{Conclusion}

Exercise training could positively affect risk factors associated with CVD. There are certain exercise parameters that may be of greater benefit than others. Based on the findings of this study, 
engaging in regular exercise could be beneficial in addressing the physical, physiological, and psychological risk factors for CVD. The pattern, timing, intensity, and volume of those exercises should be considered in their prescription. Such parameters should be used as a guide when addressing the non-pharmacological treatment of patients with CVD.

\section{Conflict of Interest}

The authors declare that they have no conflict of interest.

\section{Funding}

This study is supported by university of Tehran (Grant number: 30701.1.4).

\section{References}

1. Sarrafzadegan N, Mohammmadifard N. Cardiovascular disease in Iran in the last 40 years: prevalence, mortality, morbidity, challenges and strategies for cardiovascular prevention. Arch Iran Med 2019; 22(4): 204-210. https://pubmed.ncbi.nlm.nih.gov/31126179.

2. Kurian AK, Cardarelli KM. Racial and ethnic differences in cardiovascular disease risk factors: a systematic review. Ethn Dis 2007; 17(1): 143-152. https://pubmed.ncbi.nlm.nih.gov/17274224.

3. Kargarfard M, Lam ETC, Shariat A, Asle Mohammadi M, Afrasiabi S, Shaw I, et al. Effects of endurance and high intensity training on ICAM1 and VCAM-1 levels and arterial pressure in obese and normal weight adolescents. Phys Sportsmed 2016; 44(3): 208-216. https://doi.org/10.1080/00913847.2016.1200442.

4. Scannapieco FA, Bush RB, Paju S. Associations between periodontal disease and risk for atherosclerosis, cardiovascular disease, and stroke. A systematic review. Ann Periodontol 2003; 8(1): 38-53. https://doi.org/10.1902/annals.2003.8.1.38.

5. Zaidi $\mathrm{H}$, Byrkjeland $\mathrm{R}$, Njerve IU, Åkra S, Solheim $\mathrm{S}$, Arnesen $\mathrm{H}$, et al. Effects of exercise training on inflammasome-related mediators and their associations to glucometabolic variables in patients with combined coronary artery disease and type 2 diabetes mellitus: Substudy of a randomized control trial. Diab Vasc Dis Res 2019; 16(4): 360368. https://doi.org/10.1177/1479164119836922.

6. Nonterah EA, Crowther NJ, Oduro A, Agongo G, Micklesfield LK, Boua $\mathrm{PR}$, et al. Poor cardiovascular health is associated with subclinical atherosclerosis in apparently healthy sub-Saharan African populations: an H3Africa AWI-Gen study. BMC Med 2021; 19(1): 1-12. https://doi.org/10.1186/s12916-021-01909-6.

7. Lan C, Chen SY, Wong MK, Lai JS. Tai chi chuan exercise for patients with cardiovascular disease. Evid Based Complement Alternat Med 2013; 2013: 983208. https://doi.org/10.1155/2013/983208.

8. Jeong SW, Kim SH, Kang SH, Kim HJ, Yoon CH, Youn TJ, et al. Mortality reduction with physical activity in patients with and without cardiovascular disease. Eur Heart J 2019; 40(43): 3547-3555. https://doi.org/10.1093/eurheartj/ehz564.

9. Kargarfard M, Shariat A, Shaw BS, Shaw I, Lam ETC, Kheiri A, et al. Effects of Polluted Air on Cardiovascular and Hematological Parameters After Progressive Maximal Aerobic Exercise. Lung 2015; 193(2): 275-281. https://doi.org/10.1007/s00408-014-9679-1.

10. Kraus WE, Powell KE, Haskell WL, Janz KF, Campbell WW, Jakicic JM, et al. Physical activity, all-cause and cardiovascular mortality, and cardiovascular disease. Med Sci Sports Exerc 2019; 51(6): 1270-1281. https://doi.org/10.1249/mss.0000000000001939.

11. Pate RR, Pratt M, Blair SN, Haskell WL, Macera CA, Bouchard C, et al. Physical activity and public health: a recommendation from the Centers for Disease Control and Prevention and the American College of Sports Medicine. JAMA 1995; 273(5): 402-407. https://doi.org/10.1001/jama.273.5.402.
12. Woodcock J, Franco OH, Orsini N, Roberts I. Non-vigorous physical activity and all-cause mortality: systematic review and meta-analysis of cohort studies. Int J Epidemiol 2011; 40(1): 121-138. https://doi.org/10.1093/ije/dyq104.

13. Toukhsati SR, Jovanovic A, Dehghani S, Tran T, Tran A, Hare DL. Low psychological resilience is associated with depression in patients with cardiovascular disease. Eur J Cardiovasc Nurs 2017; 16(1): 64-69. https://doi.org/10.1177/1474515116640412.

14. Stanek KM, Gunstad J, Paul RH, Poppas A, Jefferson AL, Sweet LH, et al. Longitudinal cognitive performance in older adults with cardiovascular disease: evidence for improvement in heart failure. J Cardiovasc Nurs 24(3):

192-197. https://doi.org/10.1097/jcn.0b013e31819b54de.

15. Lawes CMM, Vander Hoorn S, Rodgers A. Global burden of bloodpressure-related disease, 2001. Lancet 2008; 371(9623): 1513-1518. https://doi.org/10.1016/s0140-6736(08)60655-8.

16. Sarmento AO, Antunes-Correa LM, Alves MJNN, Bacurau AVN, Fonseca $\mathrm{KCB}$, Pessoa FG, et al. Effect of exercise training on cardiovascular autonomic and muscular function in subclinical Chagas cardiomyopathy: a randomized controlled trial. Clin Auton Res 2020; 31(2): 239-251. https://doi.org/10.1007/s10286-020-00721-1.

17. Witvrouwen I, Mannaerts D, Van Berendoncks AM, Jacquemyn Y, Van Craenenbroeck EM. The Effect of Exercise Training During Pregnancy to Improve Maternal Vascular Health: Focus on Gestational Hypertensive Disorders. Front Physiol 2020; 11: 450. https://doi.org/10.3389/fphys.2020.00450.

18. Larsen $\mathrm{AH}$, Wiggers $\mathrm{H}$, Dollerup $\mathrm{OL}$, Jespersen NR, Hansson $\mathrm{NH}$, Frøkiær J, et al. Metformin Lowers Body Weight But Fails to Increase Insulin Sensitivity in Chronic Heart Failure Patients without Diabetes: a Randomized, Double-Blind, Placebo-Controlled Study. Cardiovasc Drugs Ther 2020; 35(3): 491-503. https://doi.org/10.1007/s10557-02007050-5.

19. Knowler WC, Barrett-Connor E, Fowler SE, Hamman RF, Lachin JM, Walker EA, et al. Reduction in the incidence of type 2 diabetes with lifestyle intervention or metformin. N Engl J Med 2002; 346(6): 393403. https://doi.org/10.1056/nejmoa012512.

20. Villafaina S, Collado-Mateo D, Fuentes JP, Merellano-Navarro E, Gusi N. Physical exercise improves heart rate variability in patients with type 2 diabetes: a systematic review. Curr Diab Rep 2017; 17(11): 110. https://doi.org/10.1007/s11892-017-0941-9.

21. Crisafulli A, Pagliaro P, Roberto S, Cugusi L, Mercuro G, Lazou A, et al. Diabetic cardiomyopathy and ischemic heart disease: prevention and therapy by exercise and conditioning. Int J Mol Sci 2020; 21(8): 2896. https://doi.org/10.3390/ijms21082896.

22. Cui Y, Blumenthal RS, Flaws JA, Whiteman MK, Langenberg P, Bachorik PS, et al. Non-high-density lipoprotein cholesterol level as a predictor of cardiovascular disease mortality. Arch Intern Med 2001; 161(11): 1413-1419. https://doi.org/10.1001/archinte.161.11.1413.

23. Halbert JA, Silagy CA, Finucane P, Withers RT, Hamdorf PA. Exercise training and blood lipids in hyperlipidemic and normolipidemic adults: a meta-analysis of randomized, controlled trials. Eur J Clin Nutr 1999; 53(7): 514-522. https://doi.org/10.1038/sj.ejcn.1600784.

24. Oranwa JC, Ogbu IS, Ikekpeazu JE, Onyekwelu KC, Esom EA, Ugonabo MC. Lipid profile of people engaged in regular exercise. Ann Med Health Sci Res 2017; 7: 36-39. https://www.amhsr.org/articles/lipidprofile-of-people-engaged-in-regular-exercise-3817.html.

25. Ismail KA, Elsayyad L, Allam HH, Alzahrani N, Gharib AF. Effect of ShortTerm Aerobic Exercise on Lipid Profile. Biomed Sci J 2020; 1; 05. https://cienciaworld.com/Effect-of-Short-Term-Aerobic-Exercise-onLipid-Profile.pdf.

26. Konukoglu D, Uzun H. Endothelial dysfunction and hypertension. Adv Exp Med Biol 2017; 956: 511-540. https://doi.org/10.1007/5584 201690.

27. Alem MM. Endothelial dysfunction in chronic heart failure: assessment, findings, significance, and potential therapeutic targets. 
Int J Mol Sci 2019; 20(13): 3198. https://doi.org/10.3390/ijms20133198.

28. Gevaert $A B$, Lemmens $K$, Vrints $C J$, Van Craenenbroeck EM. Targeting endothelial function to treat heart failure with preserved ejection fraction: the promise of exercise training. Oxid Med Cell Longev 2017; 2017: 4865756. https://doi.org/10.1155/2017/4865756

29. Kato M, Masuda T, Ogano M, Hotta K, Takagi H, Tanaka S, et al. Stretching exercises improve vascular endothelial dysfunction through attenuation of oxidative stress in chronic heart failure patients with an implantable cardioverter defibrillator. J Cardiopulm Rehabil Prev 2017; 37(2): 130-138. https://doi.org/10.1097/hcr.0000000000000229.

30. Lin $\mathrm{S}$, Zhang $\mathrm{H}, \mathrm{Ma} \mathrm{A}$. The association between depression and coronary artery calcification: A meta-analysis of observational studies. J Affect Disord 2018; 232: 276-282. https://doi.org/10.1016/i.jad.2018.02.027.

31. Carney RM, Freedland KE. Depression and coronary heart disease. Nat Rev Cardiol 2017; 14(3): 145-155. https://doi.org/10.1038/nrcardio.2016.181.

32. Vaccarino V, Badimon L, Bremner JD, Cenko E, Cubedo J, Dorobantu M, et al. Depression and coronary heart disease: 2018 position paper of the ESC working group on coronary pathophysiology and microcirculation. Eur Heart J 2020; 41(17): 1687-1696. https://doi.org/10.1093/eurhearti/ehy913.

33. Barbaresko J, Rienks J, Nöthlings U. Lifestyle indices and cardiovascular disease risk: a meta-analysis. Am J Prev Med 2018; 55(4): 555-564. https://doi.org/10.1016/i.amepre.2018.04.046.

34. Kachur S, Chongthammakun V, Lavie CJ, De Schutter A, Arena R, Milani $\mathrm{RV}$, et al. Impact of cardiac rehabilitation and exercise training programs in coronary heart disease. Prog Cardiovasc Dis 2017; 60(1): 103-114. https://doi.org/10.1016/i.pcad.2017.07.002.

35. Hollings $M$, Mavros $Y$, Freeston J, Fiatarone Singh $M$. The effect of progressive resistance training on aerobic fitness and strength in adults with coronary heart disease: a systematic review and metaanalysis of randomised controlled trials. Eur J Prev Cardiol 2017; 24(12): 1242-1259. https://doi.org/10.1177/2047487317713329.

36. Marzolini S, Oh PI, Brooks D. Effect of combined aerobic and resistance training versus aerobic training alone in individuals with coronary artery disease: a meta-analysis. European journal of preventive cardiology. 2012; 19(1): 81-94. https://doi.org/10.1177/1741826710393197.

37. Yamamoto S, Hotta K, Ota E, Mori R, Matsunaga A. Effects of resistance training on muscle strength, exercise capacity, and mobility in middle-aged and elderly patients with coronary artery disease: A $\begin{array}{llll}\text { meta-analysis. J Cardiol 2016; 68(2): 125-134 } & \end{array}$ https://doi.org/10.1016/j.jjcc.2015.09.005

38. Liu Y, Lee DC, Li Y, Zhu W, Zhang R, Sui X, et al. Associations of resistance exercise with cardiovascular disease morbidity and mortality. Med Sci Sports Exerc 2019; 51(3): 499-508. https://doi.org/10.1249/mss.0000000000001822.

39. Braith RW, Stewart KJ. Resistance exercise training: its role in the prevention of cardiovascular disease. Circulation 2006; 113(22): 26422650. https://doi.org/10.1161/circulationaha.105.584060.

40. Taylor JL, Holland DJ, Keating SE, Leveritt MD, Gomersall SR, Rowlands $A V$, et al. Short-term and Long-term Feasibility, Safety, and Efficacy of High-Intensity Interval Training in Cardiac Rehabilitation: The FITR Heart Study Randomized Clinical Trial. JAMA Cardiol 2020; 5(12): 13821389. https://doi.org/10.1001/jamacardio.2020.3511.

41. Dorn J, Naughton J, Imamura D, Trevisan M. Results of a multicenter randomized clinical trial of exercise and long-term survival in myocardial infarction patients: the National Exercise and Heart Disease Project (NEHDP). Circulation 1999; 100(17): 1764-1769. https://doi.org/10.1161/01.cir.100.17.1764.

42. Hvas AM, Neergaard-Petersen S. Influence of exercise on platelet function in patients with cardiovascular disease. Semin Thromb
Hemost 2018; 44(8): 802-812. https://doi.org/10.1055/s-00381673618.

43. Claes J, Buys R, Budts W, Smart N, Cornelissen VA. Longer-term effects of home-based exercise interventions on exercise capacity and physical activity in coronary artery disease patients: A systematic review and meta-analysis. Eur J Prev Cardiol 2017; 24(3): 244-256. https://doi.org/10.1177/2047487316675823.

44. Kraal JJ, Vromen $T$, Spee $R$, Kemps HMC, Peek N. The influence of training characteristics on the effect of exercise training in patients with coronary artery disease: systematic review and meta-regression analysis. Int J Cardiol 2017; 245: 52-58. https://doi.org/10.1016/i.ijcard.2017.07.051.

Authors:

Mahboubeh Ghayour Najafabadi - PhD, Associate Professor, Department of Motor Behavior, Faculty of Physical Education and Sport Sciences, University of Tehran, Tehran, Iran. https://orcid.org/0000-0002-2350-4514. Amir Sobhrakhshan Khah - MD, Associate Professor, Sepehr Heart Center, Baharloo Hospital, Tehran University of Medical Sciences, Tehran, Iran. https://orcid.org/0000-0003-4371-6626.

Jennifer Parent-Nichols - DPT, EdD, Board Certified Pediatric Specialist in Physical Therapy, Clinical Associate Professor, Tufts University School of Medicine, Doctor of Physical Therapy Program, Boston, USA. https://orcid.org/0000-0002-1346-6462. 